\section{Kidney \\ Blood Pressure Research}

Kidney Blood Press Res 2016;41:158-167

DOI: $10.1159 / 000443417$

Published online: February 29, 2016

Accepted: January 28, 2016

\title{
Sinomenine Attenuates Angiotensin II- Induced Autophagy via Inhibition of P47- Phox Translocation to the Membrane and Influences Reactive Oxygen Species Generation in Podocytes
}

\author{
Weili Wang ${ }^{\mathrm{a}}$ Juan Cai ${ }^{\mathrm{a}}$ Sha Tang ${ }^{\mathrm{a}}$ Ying Zhang ${ }^{\mathrm{a}} \quad$ Xuejing Gao ${ }^{\mathrm{a}}$ Lijiao Xie $^{\mathrm{a}}$ \\ Zhirong Mou $^{\mathrm{b}}$ Yuzhang Wu ${ }^{\mathrm{b}}$ Li Wang ${ }^{\mathrm{b}}$ Jingbo Zhang ${ }^{\mathrm{a}}$ \\ aDepartment of Nephrology, Xinqiao Hospital, ' Institute of Immunology of PLA, Third Military Medical \\ University, Chongqing, China
}

\section{Key Words}

Sinomenine $\bullet$ Podocyte $\cdot$ Autophagy $・$ Angiotensin II $・$ NADPH oxidase $\bullet$ p47-phox

\begin{abstract}
Background/Aims: Sinomenine, a pure alkaloid extracted from the Chinese medicinal plant Sinomenium acutum, and sinomenine hydrochloride (SN) has been successfully used for the therapy of rheumatoid arthritis (RA) and kidney diseases. Autophagy is a cytoprotective mechanism used by podocytes and other cells to alleviate the effects of oxidative stress, and angiotensin II (Ang II) significantly promotes podocyte autophagy. However, excessive autophagy may lead to cell death and podocyte depletion. The present study evaluated the effect of SN in podocytes induced by Ang II. Methods: Podocytes were pretreated with graded concentrations $\left(10^{-8} \mathrm{M} \sim 10^{-4} \mathrm{M}\right)$ of SN and then stimulated with Ang II. The LC3B protein and the p47-phox membrane fraction were measured by Western blot. Autolysosomes were assessed by transmission electron microscopy. FACS was used to quantify the ROS produced by podocytes. The translocation of p47-phox to the membrane was investigated by immunofluorescence. Results: The $10^{-8} \mathrm{M} \sim 10^{-4} \mathrm{M}$ of SN alone did not effect ROS generation or podocyte autophagy. The $10^{-8} \mathrm{M}$ and $10^{-6} \mathrm{M}$ SN attenuated Ang II-induced autophagy in podocytes. Furthermore, SN decreased the level of ROS generation in Ang II-induced podocytes via inhibition of NOX subunit p47-phox translocation to the membrane. Conclusion: The appropriate concentration of SN attenuated Ang II-induced podocyte autophagy through ROS generation, at least in part, by regulating NOX subunit p47-phox translocation to the membrane.

Weili Wang and Juan Cai contributed equally to this work and therefore share first authorship.




\section{Kidney \\ Blood Pressure Research}

Kidney Blood Press Res 2016;41:158-167

\begin{tabular}{l|l}
\hline DOI: 10.1159/000443417 & (C) 2016 The Author(s). Published by S. Karger AG, Base
\end{tabular}

Published online: February 29, 2016

www.karger.com/kb

\section{Introduction}

Podocytes, as highly differentiated cells, are important constituents of the glomerular filtration barrier [1], which prevent the loss of plasma proteins and have numerous critical biological functions. Podocytes are often exposed to various damaging factors, which can potentially induce oxidative stress and DNA damage [2-5]. Injured podocytes play a key factor in the pathogenesis of glomerular diseases and the progression of renal failure. Podocytes survival is dependent on autophagy to efficiently sequester unwanted or damaged proteins/ organelles into autophagosomes [6]. Podocytes are cells with high levels of basal autophagy $[7,8]$. Autophagy includes the autophagic flux consisting of the fusion of autophagosomes to lysosomes and the lysosomal enzymatic degradation of these autophagic substances, which keeping podocytes in a differentiated and functional status [9]. However, excessive autophagy may lead to cell death [10].

Autophagy is a response to diverse conditions of stress [11,12], and it has a dual role in cell survival and cell death. Autophagic cell death has been observed in response to oxidative stress [13]. Increasing evidence argues for oxidative stress acting as the converging point of these stimuli, with reactive oxygen species (ROS) initiating autophagosome formation and modulating the autophagy process $[14,15]$. The concentration of endogenous angiotensin II (Ang II) in the kidney cortical and medullary regions were 60 100 times higher than in the arterial plasma [16]. Ang II also promotes podocyte autophagy that is dependent on the ROS generation [11].

There are two major sources for ROS production in cells, mitochondria and nicotinamide adenine dinucleotide phosphate (NADPH)-oxidase (NOX), which actively produces superoxide across the membranes $[17,18]$. NOX is a multi-component enzyme for ROS generation, consisting of a catalytic subunit NOX2/gp91-phox and p22 phox, and several cytosolic regulatory subunits, including p47-phox and p67-phox [19, 20]. The p47-phox protein, a major regulatory subunit, is located at the plasma membrane and assembles with other subunits that are required for the full activation of NOX [21].

Sinomenine $(9 \alpha, 13 \alpha, 14 \alpha)$-7,8-didehydro-4-hydroxy-3,7-dimethoxy-17-methyl-morphinane6-one], a pure alkaloid extracted from the Chinese medicinal plant Sinomenium acutum, possesses various pharmacological activities due to its complex chemical composition, and its pharmacological profile includes immunosuppression, arthritis amelioration, and antiinflammation. Sinomenine hydrochloride (SN) (Fig. 1, from the datasheet of Sinomenine hydrochloride producted by abcam, ab141190) has successfully been used in the therapy of rheumatoid arthritis (RA) and kidney diseases. It has superior therapeutic effects and relatively few side effects [22-24], but the mechanism by which SN acts remains unclear. Recent studies indicated that the lower concentrations $\left(10^{-14} \sim 10^{-4} \mathrm{M}\right)$ of SN can decrease microglial cell ROS generation and confers neuroprotection $[25,26]$. Whereas, the higher concentrations $\left(10^{-4} \sim 10^{-1} \mathrm{M}\right)$ of SN also have anti-inflammatory effects via the regulation of autophagy activities [27, 28].

On the basis of ROS as an important mediator in autophagy, we hypothesized the lower concentrations $\left(10^{-8}\right.$ $\sim 10^{-4} \mathrm{M}$ ) of SN may attenuate podocyte autophagy. In this study, we investigated the effects of SN on Ang II-induced podocyte autophagy and the mechanism of protection caused by its regulation of the NOX subunit, p47-phox.

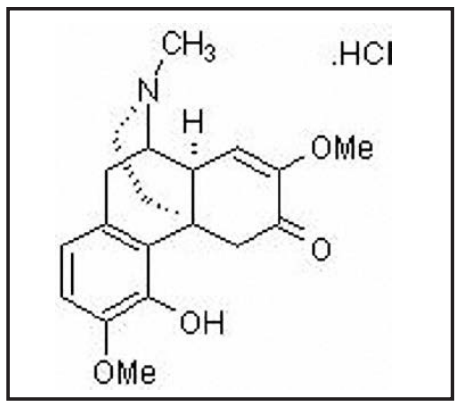

Fig. 1. The structure of sinomenine hydrochloride (SN) . 


\section{Kidney Blood Pressure Research}

Kidney Blood Press Res 2016;41:158-167

\begin{tabular}{l|l}
\hline DOI: 10.1159/000443417 & (C) 2016 The Author(s). Published by S. Karger AG, Base
\end{tabular}

Published online: February 29, 2016

www.karger.com/kb

Wang/Cai/Tang/Zhang/Gao/Xie/Mou/Wu/Wang/Zhang: SN Attenuates Ang II-Induced

Autophagy in Podocytes

\section{Reagents}

Fetal bovine serum (FBS) and RPMI 1640 were purchased from Gibco (NY, USA). The ITS (containing $10 \mu \mathrm{g} / \mathrm{ml}$ insulin, $0.55 \mathrm{mg} / \mathrm{ml}$ human transferrin and $0.5 \mu \mathrm{g} / \mathrm{ml}$ sodium selenite), rabbit anti-human LC3B polyclonal antibody and diphenyleneiodonium chloride (DPI) were purchased from Sigma-Aldrich (St. Louis, MO, USA). Angiotensin II (Ang II) was purchased from Biovision (Milpitas, USA). Sinomenine hydrochloride (SN) was obtained from Zhengqing Pharmaceutical Group (HuNan, China). Rabbit anti-human p47-phox polyclonal antibody for immunofluorescence was purchased from Santa Cruz (Santa Cruz, CA, USA). Rabbit anti-human p47-phox polyclonal antibody for Western blot was purchased from Bioworld (MN, USA). The Membrane Protein Extraction kit was purchased from BestBio (ShangHai, China). The Enhanced BCA Protein Assay Kit, reactive oxygen species kit, mouse anti human $\beta$-actin monoclonal antibody, HRP-labeled goat anti-rabbit IgG, HRP-labeled goat anti-mouse IgG, Alexa Fluor 488-labeled goat anti-rabbit IgG, Hoechst 33342, RIPA lysis buffer (50 mM Tris, $150 \mathrm{mM} \mathrm{NaCl}, 1 \%$ Triton X-100, 1\% sodium deoxycholate, $0.1 \%$ SDS, pH 7.4) and the protease inhibitor phenylmethanesulfonylfluoride (PMSF) were all purchased from Beyotime (Shanghai, China).

\section{Podocyte culture and treatment}

Immortalized human podocytes (AB8/13) were a kind gift from Dr. Moin A. Saleem (University of Bristol, UK). Podocytes were maintained in RPMI 1640 containing 10\% FBS, ITS, penicillin and streptomycin at $33^{\circ} \mathrm{C}$ in $95 \%$ air, $5 \% \mathrm{CO}_{2}$. After reaching $70 \%$ confluence, the cells were transferred to $37^{\circ} \mathrm{C}$ in $95 \%$ air, $5 \% \mathrm{CO}_{2}$ and cultured for 14 days for differentiation [29]. The differentiated podocytes show morphology with multiple foot processes, and only differentiated cells were used for experiments. Cells were stimulated with $10^{-7} \mathrm{M}$ Ang II for $24 \mathrm{~h}$ as previously described [11] or with medium alone. In some experiments, cells were treated with graded concentrations $\left(10^{-8} \mathrm{M} \sim 10^{-4} \mathrm{M}\right)$ of SN alone for $24 \mathrm{~h}$ or pretreated for $1 \mathrm{~h}$ before stimulation with Ang II.

\section{Reactive oxygen species determination}

The level of intracellular ROS produced in podocytes was quantified using the fluorescent signal from the redox-sensitive fluoroprobe 2', 7'- dichlorofluorescein diacetate (DCFH-DA) according to the protocol provided by the manufacturer (Beyotime, China). Cells were grown in 6-well plates in serum-free culture medium for $24 \mathrm{~h}$. The podocytes were treated as previously described. The cells were then washed twice with PBS and then incubated with DCFH-DA $(5 \mu \mathrm{M})$ in medium at $37^{\circ} \mathrm{C}$ for $30 \mathrm{~min}$ in the dark. Then, the cells were washed with PBS and the fluorescent intensity was measured with a flow cytometer using an excitation wavelength of $488 \mathrm{~nm}$ and an emission wavelength of $525 \mathrm{~nm}$ (BD Accuri C6, USA).

\section{Immunofluorescence analysis}

Podocytes were plated on poly-L-lysine treated coverslips at $37^{\circ} \mathrm{C}$ for $24 \mathrm{~h}$. After treatment, the cells were fixed with $4 \%$ paraformaldehyde for $15 \mathrm{~min}$ and blocked with $5 \%$ bovine serum albumin (BSA) for $1 \mathrm{~h}$. Then, the cells were incubated with rabbit anti human p47-phox polyclonal antibody (diluted 1:50, Santa Cruz) at $4{ }^{\circ} \mathrm{C}$ overnight and then conjugated with Alexa Fluor 488-labeled goat anti-rabbit IgG (diluted 1:1000) at room temperature for $1 \mathrm{~h}$ in the dark. After staining with Hoechst 33342 for 5 min, the coverslips were sealed with glycerol jelly mounting medium for detection. Images were captured with a fluorescence microscope (Nikon, Japan) from random microscope fields and analyzed using Image-Pro Plus 6.

\section{Protein Extraction and Western blot analysis}

The total LC3B protein and membrane protein p47-phox of the podocytes were analyzed by Western blot. During the total protein extraction, the podocytes were washed with EDTA and harvested using a cell scraper after treatment. Next, the samples were lysed with RIPA lysis buffer containing PMSF. For the membrane protein extraction, each sample contained $5 \times 10^{6}$ podocytes, which were cultured in 75 $\mathrm{cm}^{2}$ plastic culture flasks. After treatment, cells were washed with EDTA and collected with a cell scraper. Then, all procedures were performed according to the protocol for the Membrane Protein Extraction kit for extracting the membrane protein p47-phox (BestBio, China). Protein concentrations of the samples were determined using a BCA protein assay. Each protein lysate was separated by $10 \%$ SDS-PAGE and transferred 


\section{Kidney Blood Pressure Research}

Kidney Blood Press Res 2016;41:158-167

\begin{tabular}{l|l}
\hline DOI: 10.1159/000443417 & (C) 2016 The Author(s). Published by S. Karger AG, Base
\end{tabular}

Published online: February 29, 2016

www.karger.com/kb

to polyvinylidene difluoride (PVDF) membranes. Subsequently, PVDF membranes were blocked with 5\% nonfat milk at room temperature for $1 \mathrm{~h}$ and then incubated with the appropriate dilution of primary antibodies (p47-phox, diluted 1:500; LC3B, diluted 1:1000; $\beta$-actin diluted 1:500) at $4^{\circ} \mathrm{C}$ overnight. Then, the membranes were incubated for $1 \mathrm{~h}$ at room temperature with HRP-labeled goat anti-rabbit IgG or HRPlabeled goat anti-mouse IgG secondary antibody (diluted 1:1000). Following washing, the membranes were detected by ECL according to the manufacturer's instructions.

Transmission electron microscopy investigation

Podocytes were fixed in $2.5 \%$ glutaraldehyde and post-fixed in $1 \%$ osmium tetroxide. Then, the samples were dehydrated in a graded ethanol series and propylene oxide and embedded on molds containing pure Spurr's resin. Ultrathin sections were contrasted with uranyl acetate and lead citrate and imaged with a JEM-1400 plus electron microscope (JEOL, Japan).

Statistical analysis

All data are expressed as the means \pm SEM, and one-way ANOVA combined with Student-NewmanKeuls were used to compare the differences between multiple groups using the Graphpad Prism 6 software. A value of $p<0.05$ was considered statistically significant.

\section{Results}

Sinomenine attenuates Ang II-induced autophagy in podocytes

To study the effect of SN on Ang II-induced autophagy, we first determined whether SN alone promoted podocyte autophagy. Podocytes were incubated with $10^{-7} \mathrm{M}$ Ang II or $10^{-8}$ $\mathrm{M} \sim 10^{-4} \mathrm{M}$ of SN alone for $24 \mathrm{~h}$. Total protein of the podocytes was extracted and measured by Western blot. The LC3B-II/actin ratio was used as an autophagy biomarker. As previously reported [11], the LC3B-II/actin ratio was significantly increased in Ang II-induced cells compared with the control group, but $10^{-8} \mathrm{M} \sim 10^{-4} \mathrm{M}$ SN alone had no significant effect on podocyte autophagy (Fig. 2A and B). We then determined the effect of SN on Ang II-induced podocyte autophagy. Cells were pretreated with different concentrations of SN for $1 \mathrm{~h}$ and then stimulated with $10^{-7} \mathrm{M}$ Ang II for $24 \mathrm{~h}$. The podocyte autophagy increase caused by Ang II was blocked by $10^{-8} \mathrm{M}$ and $10^{-6} \mathrm{M}$ SN but was not blocked in the $10^{-4} \mathrm{M}$ SN pretreated group (Fig. 2C and D). This result demonstrated that the appropriate concentration of SN has a protective effect on Ang II-induced autophagy in podocytes.

Transmission electron microscopy is a direct and reliable method to observe autophagy by investigating autolysosomes formation [30]. Podocytes were incubated with $10^{-7} \mathrm{M}$ Ang II after pretreatment with $10^{-8} \mathrm{M} \sim 10^{-4} \mathrm{M} \mathrm{SN}$. Normal podocytes showed the formation of few autophagosomes, whereas with Ang II stimulation, the number of autolysosomes increased significantly. This phenomenon was inhibited by $10^{-8} \mathrm{M}$ and $10^{-6} \mathrm{M}$ SN but not $10^{-4} \mathrm{M}$ SN (Fig. 3A). We calculated the number of autophagosomes in five random fields from different podocytes (Fig. 3B). The results were consistent with the LC3B protein analyzed by Western blot.

\section{Sinomenine decreases the level of ROS generation in Ang II-induced podocytes}

ROS has a vital role in the generation of autophagy and is significantly increased by Ang II based on previous studies $[11,17]$; therefore, we further investigated the effect of SN on ROS generation on Ang II-induced podocytes. Podocytes were treated with $10^{-8} \mathrm{M} \sim 10^{-4} \mathrm{M}$ $\mathrm{SN}$ alone for $24 \mathrm{~h}$. In some experiments, podocytes were pretreated with SN or $10 \mu \mathrm{M}$ DPI, an inhibitor of NADPH oxidase for $1 \mathrm{~h}$. Then, the pretreated podocytes were incubated with $10^{-7}$ M Ang II for $24 \mathrm{~h}$. We found that SN alone did not affect ROS generation in podocytes (Fig. 4A). Ang II significantly promoted ROS generation compared with the medium alone group (Fig. 4B). This effect was significantly inhibited by DPI (Fig. 4C) and in the $10^{-8} \mathrm{M}$ and $10^{-6} \mathrm{M}$ SN pretreated groups (Fig. 4D and 4E). The $10^{-4} \mathrm{M}$ SN group also showed this effect but was weaker than the lower concentration group (Fig. 4F). These results showed that the lower 


\section{Kidney Blood Pressure Research}

Kidney Blood Press Res 2016;41:158-167

\begin{tabular}{l|l}
\hline DOI: $10.1159 / 000443417$ & (c) 2016 The Author(s). Published by S. Karger AG, Basel
\end{tabular}

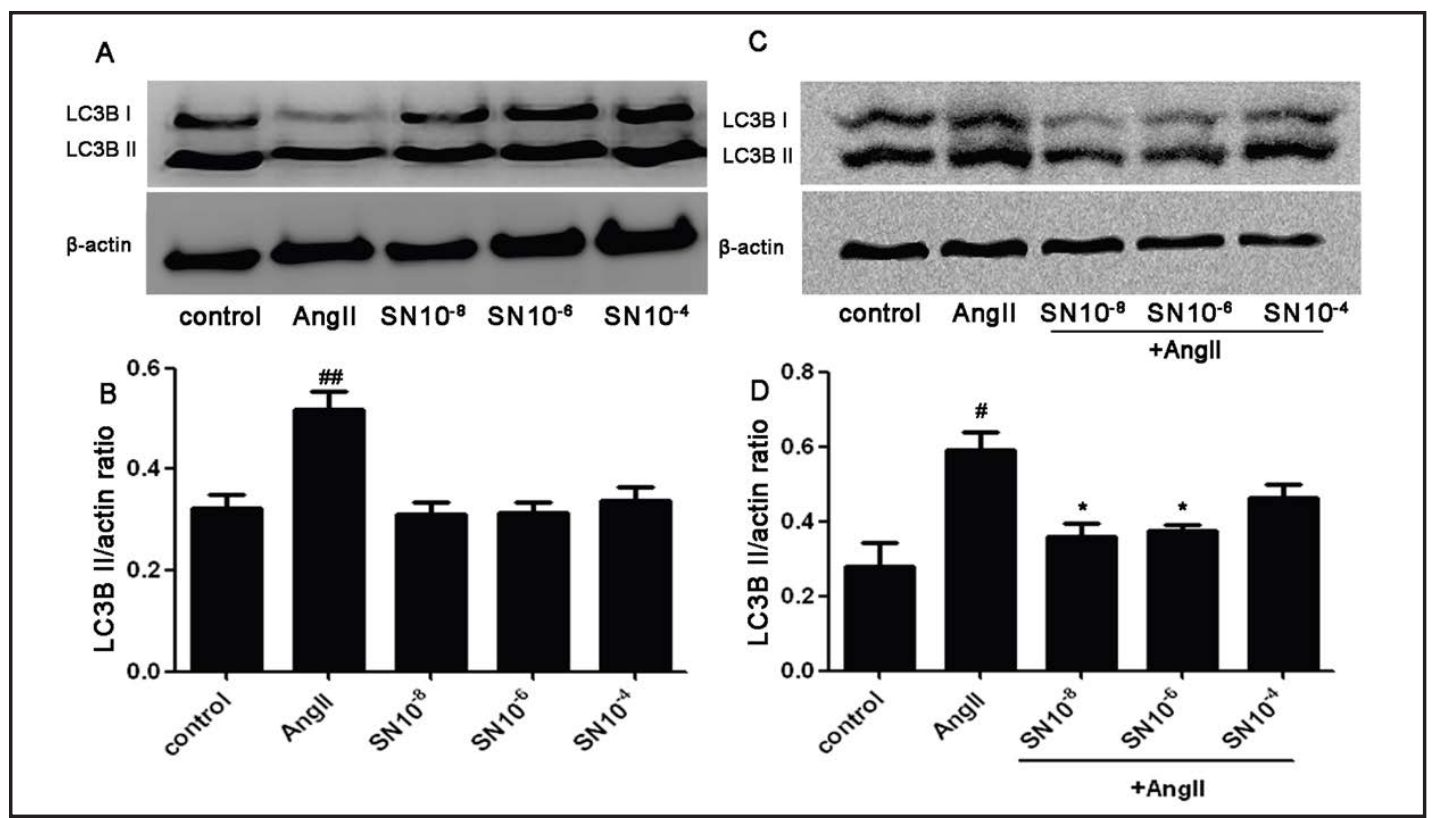

Fig. 2. The expression of LC3B in podocytes. The LC3BII/actin ratio is related to autophagy of podocytes. (A and B) Podocytes were treated with SN $\left(10^{-8} \mathrm{M} \sim 10^{-4} \mathrm{M}\right.$ ) alone for $24 \mathrm{~h}$. (C and D) Podocytes were pretreated with SN $\left(10^{-8} \mathrm{M} \sim 10^{-4} \mathrm{M}\right)$ for $1 \mathrm{~h}$ and then treated with Ang II for $24 \mathrm{~h}$. Data are presented as the means \pm SEM (n=3). ${ }^{\#} P<0.05$; ${ }^{\#} P<0.01$, compared with medium alone; ${ }^{*} P<0.05$, compared with the Ang II-treated group.

Fig. 3. Autolysosome formation was detected by transmission electron microscopy (TEM). (A) The representative autolysosomes are indicated by black arrows in the medium group. Ang II-stimulated groups with or without pretreatment using $10^{-8} \mathrm{M}$ $10^{-4}$ M SN. (B) Statistical data are shown as the numbers of autophagosomes counted in random fields from different podocytes. Data are presented as the means \pm SEM $(n=5$, from five different cells). ${ }^{\# \#} P<0.001$, compared with the medium alone group; *** $P<0.001$, compared with the Ang II-treated group.

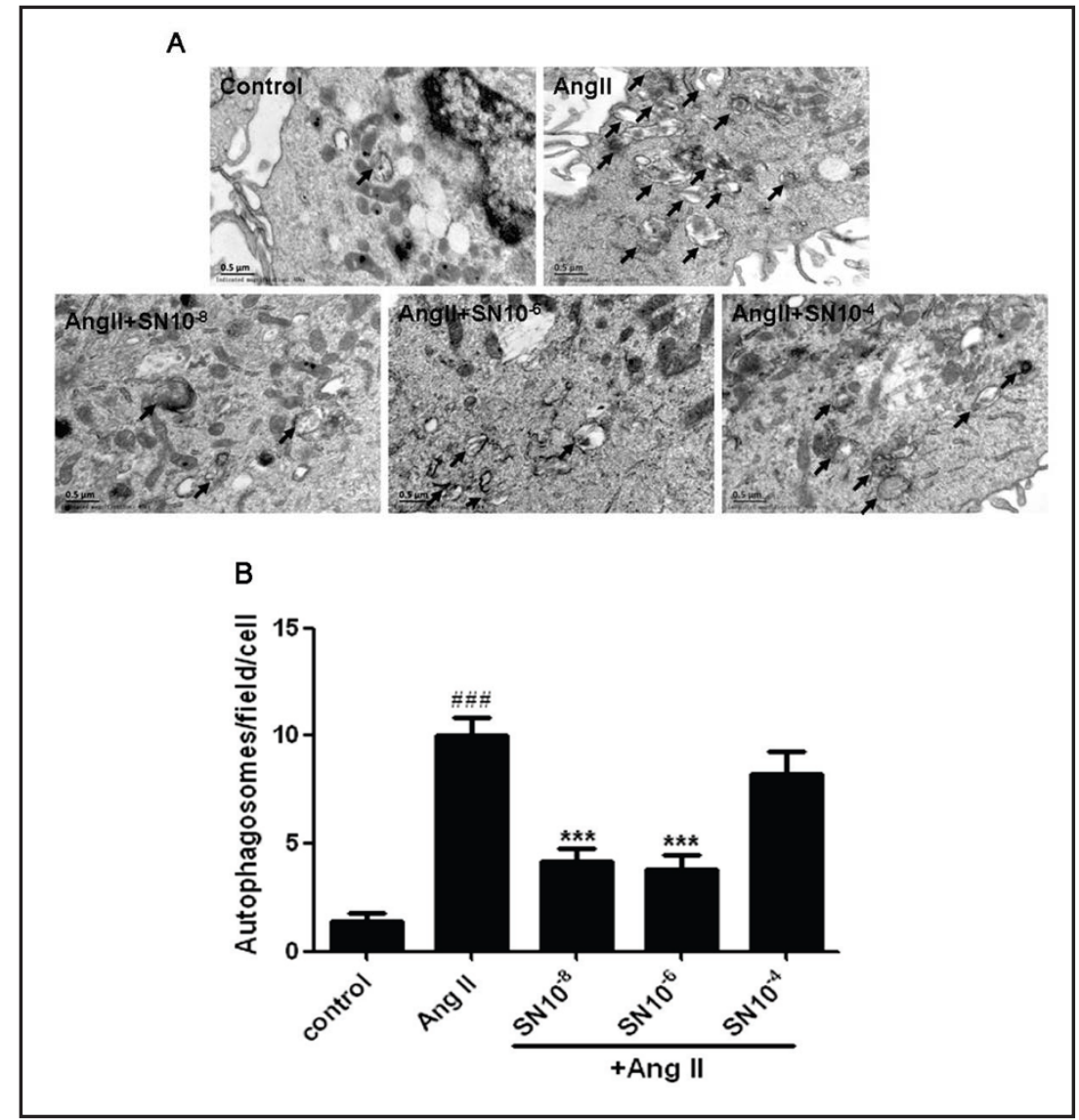




\section{Kidney Blood Pressure Research}

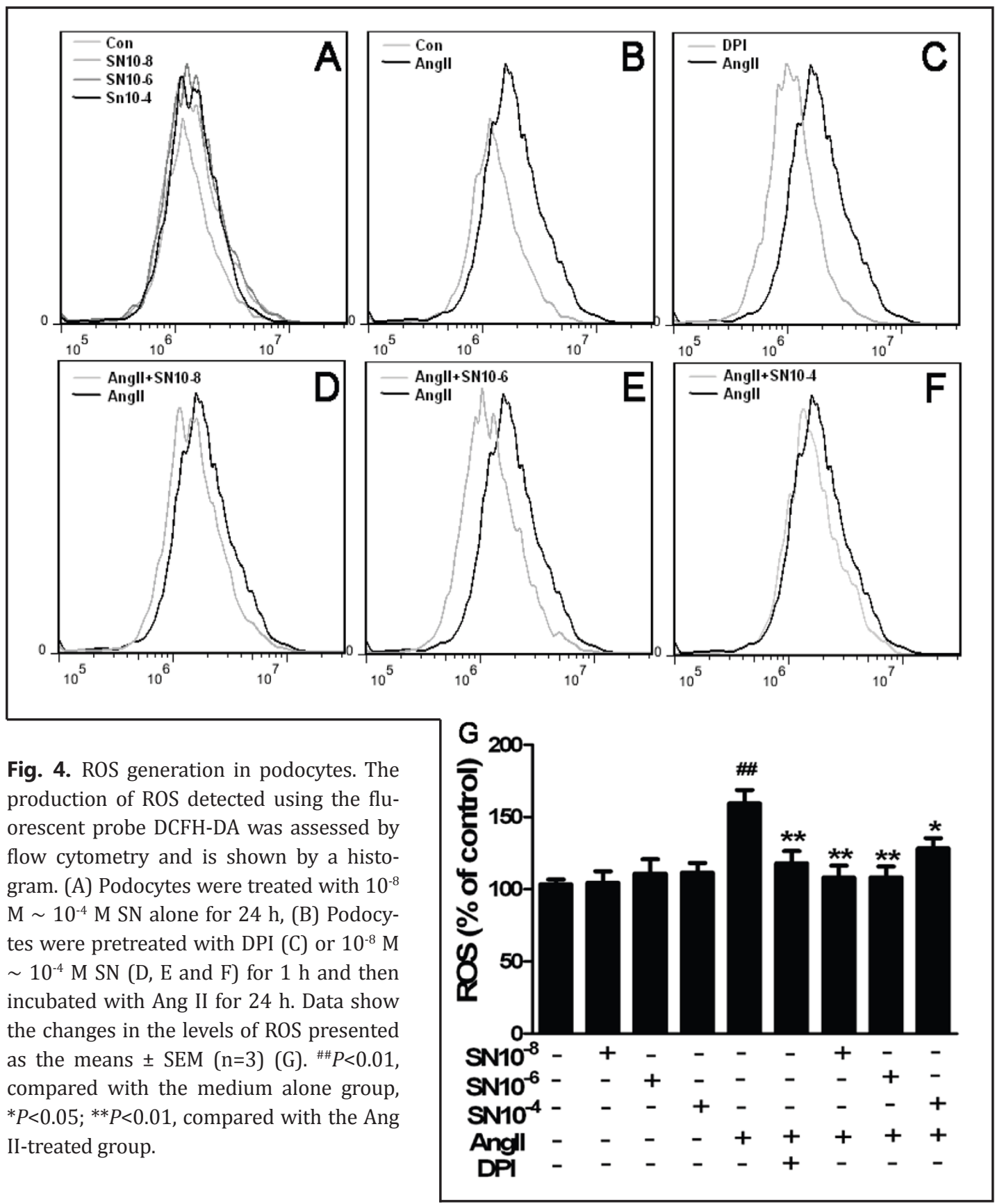

concentrations $\left(10^{-8} \mathrm{M}\right.$ and $\left.10^{-6} \mathrm{M}\right)$ of SN decreased the ROS generation induced by Ang II better than the higher concentration $\left(10^{-4} \mathrm{M}\right)$ of SN (Fig. $\left.4 \mathrm{G}\right)$, indicating that the appropriate concentrations of SN in podocytes protects against excessive ROS generation.

Sinomenine prevents $p 47$-phox translocation to the membrane

The translocation to the membrane of $\mathrm{p} 47$-phox, the main regulatory subunit of NOX, plays an important role in the full activation of NOX and ROS generation [21]. A previous study found that $\mathrm{p} 47$-phox translocation from the cytosol to membrane is induced by Ang II [31]. Here, we determined whether p47-phox translocation was prevented by SN in podocytes. Using fluorescence microscopy, we observed p47-phox expression on the membrane of podocytes induced by $10^{-7} \mathrm{M}$ Ang II for $24 \mathrm{~h}$, as shown in (Fig. 5B). The p47phox content on 


\section{Kidney Blood Pressure Research}

Fig. 5. P47-phox localization on the membrane was detected by immunofluorescence staining. P47-phox expressed under the basal state $(\mathrm{A})$, treated with $10^{-7}$ M Ang II (B) or pretreated with $10^{-8} \mathrm{M} \mathrm{SN}(\mathrm{C}), 10^{-6} \mathrm{M} \mathrm{SN}$ (D), and $10^{-4} \mathrm{M} \mathrm{SN}$ (E) before treatment with $10^{-7} \mathrm{M}$ Ang II (original magnification of 400x). Data are presented as the mean fluorescence intensity (MFI) as the means \pm SEM $(n=3$, from three random fields of each sample)

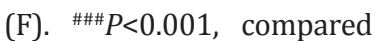
with the basal state (control), ${ }^{* * *} P<0.001$, compared with the Ang II group.

the membrane was greater for the treated cells than the control (Fig. 5A). However, podocytes pretreated with $10^{-8}$ $\mathrm{M}$ and $10^{-6} \mathrm{M}$ SN for $1 \mathrm{~h}$ showed sporadic p47-phox membrane staining, suggesting that SN prevented Ang II-induced p47-phox translocation (Fig. 5C and D). However, $10^{-4} \mathrm{M}$ SN showed weaker effects compared with the lower concentrations of SN. (Fig. 5E). The mean fluorescence intensity (MFI) was analyzed and is shown in (Fig. 5F).

Consistent with the results of the fluorescence microscopy study, we also analyzed the expression of $\mathrm{p} 47$-phox from the membrane
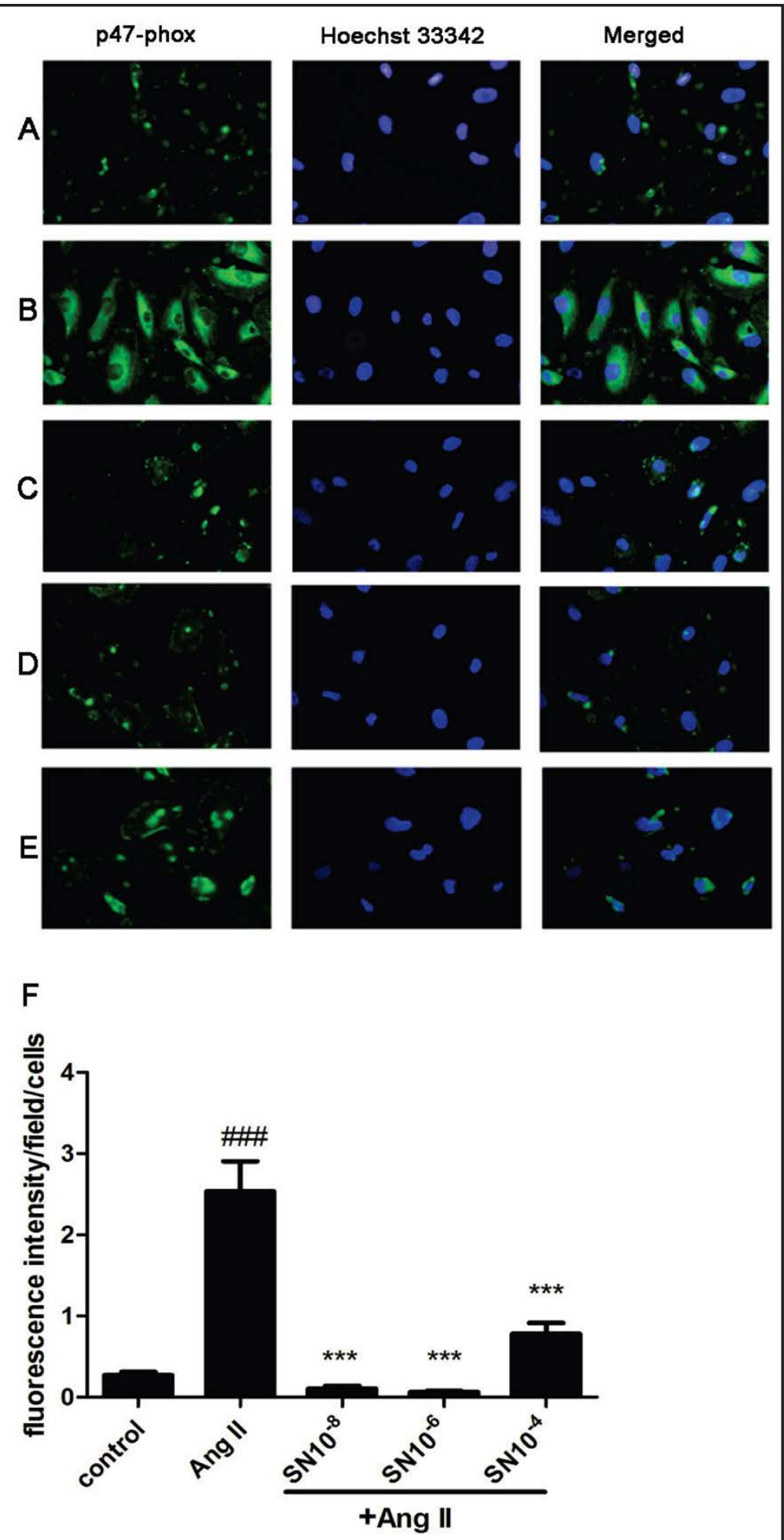

fraction of podocytes using Western blot (Fig. 6A). The increase of p47-phox in the membrane fraction of podocytes after Ang II treatment was blocked in the presence of SN at $10^{-8} \mathrm{M}$ and $10^{-6} \mathrm{M}$, but $10^{-4} \mathrm{M} \mathrm{SN}$ showed only a partial preventative effect (Fig. 6B). These results demonstrate that $\mathrm{SN}$ is protective at low concentrations, but the effect is impaired at a higher concentration. 


\section{Kidney Blood Pressure Research}

\section{Discussion}

Autophagy, which literally means "self-eating", is a catabolic process aimed at recycling cellular components and damaged proteins or organelles in response to diverse conditions of stress, such as oxidative stress [32]. Basal autophagy plays an essential role in the maintenance of cellular homeostasis, whereas excessive autophagy may lead to cell death $[10,33]$. Accumulating evidence showed that ROS plays an essential role for autophagy regulation $[11,12,32,34$, 35]. Ang II stimulates vascular smooth muscle cell ROS derived from NOX [35] and promotes autophagy in podocytes through ROS [11]. We also found that Ang II significantly increased the ROS and autophagy levels in podocytes, and the effect was inhibited with $10^{-8}$ $\mathrm{M}$ and $10^{-6} \mathrm{M}$ SN. Interestingly, the high concentration of $10^{-4}$ M SN failed to show a protective effect, indicating that $\mathrm{SN}$ has a protective effect dependent on the concentration. Some reports indicated that $\mathrm{SN}$ itself increased cell autophagy [27, 28]. However, it is notable that
Kidney Blood Press Res 2016;41:158-167

\begin{tabular}{l|l}
\hline DOI: 10.1159/000443417 & (C) 2016 The Author(s). Published by S. Karger AG, Basel
\end{tabular}

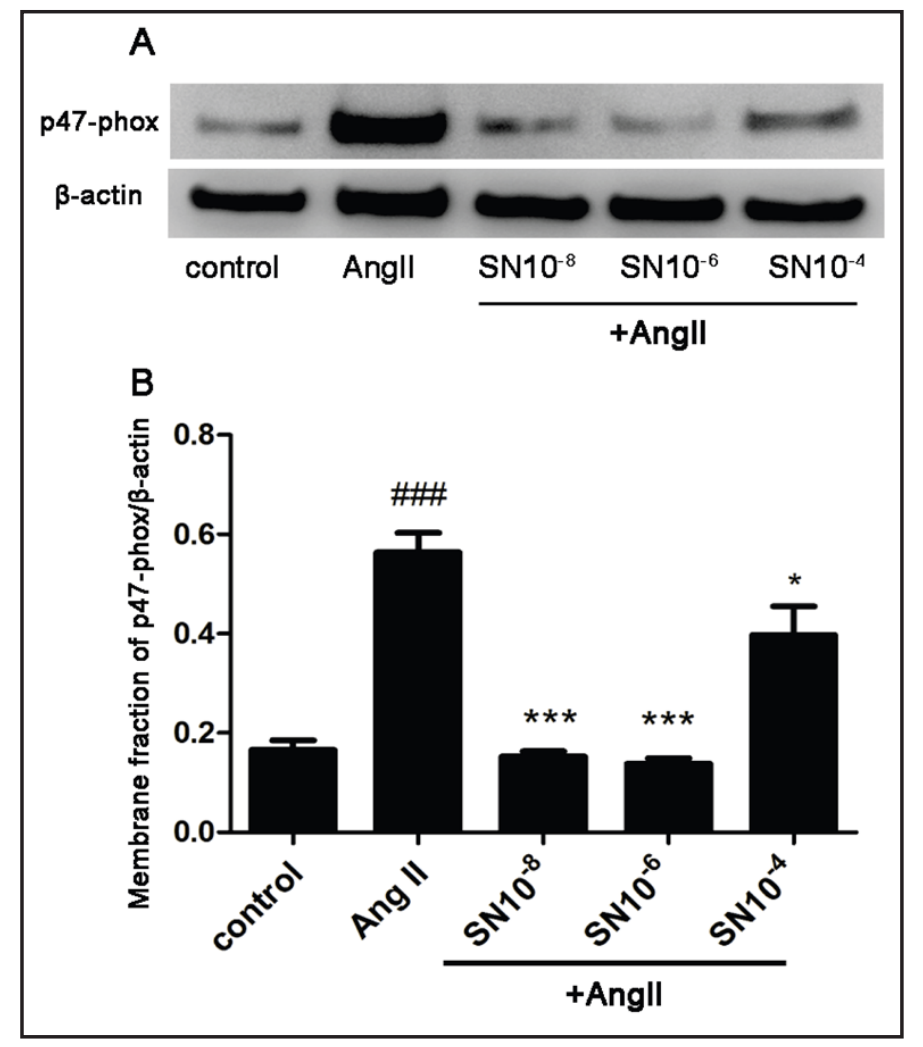

Fig. 6. The expression on $\mathrm{p} 47$-phox in the membrane fraction was assessed by Western blotting. Changes in the level of p47-phox expression in the membrane fraction from podocytes incubated in medium alone or pretreated with different concentration of SN $\left(10^{-8} \mathrm{M} \sim 10^{-4} \mathrm{M}\right)$ and then stimulated with $10^{-7} \mathrm{M}$ Ang II (A). Data are presented as the $\mathrm{p} 47$-phox/ $\beta$-actin ratio as the means \pm SEM (n=3) (B). ${ }^{\# \# \# P<0.001, ~ c o m p a r e d ~ w i t h ~ t h e ~ m e d i u m ~ g r o u p ; ~}$ ${ }^{* * *} P<0.001, * P<0.05$, compared with the Ang II group.

the concentrations of SN in those studies ranged from $10^{-4} \mathrm{M} \sim 10^{-1} \mathrm{M}$, which was higher than the concentration used in this study. In another experiment, SN inhibited LPS-induced ROS increase at concentrations of $10^{-14} \mathrm{M}$ and $10^{-5} \mathrm{M}$ but not $10^{-10} \mathrm{M}$ [25]. This demonstrated that different concentrations of SN have distinct effects on cell autophagy.

Not only do the concentrations but also the length of stimulation affects the SN protective activity. An experiment with BV2 microglial cells induced with oligomeric amyloid- $\beta$ (ADDL) showed that pretreatment with SN for $1.5 \mathrm{~h}$ successfully inhibited ADDL-induced ROS increase, whereas when ADDL and SN were added at the same time, SN failed to show the effect [26]. The study also found that SN does not affect the basal level of ROS in cells, which we also found in our study. These data suggest that multiple signaling pathways are involved in the SN inhibition mechanism, and different concentrations of SN may have different effects on cells.

In this study, we selected concentrations of SN from $10^{-8} \mathrm{M}$ to $10^{-4} \mathrm{M}$, and we found that SN significantly inhibited p47-phox expression on the membrane of Ang II-induced podocytes. This subsequently leads to decreased NOX-mediated ROS generation. However, there are some limitations to using laser confocal microscopy for investigating p47-phox translocation from the cytoplasm to the membrane in our study. The p47-phox protein contains two SH3 domains for binding to $\mathrm{p} 22$-phox and a polybasic auto-inhibitory region. These domains are 


\section{Kidney Blood Pressure Research}

masked in the resting state. Phosphorylation of p47-phox exposes these two SH3 domains for p22-phox binding and activates NOX $[19,20]$. We propose that SN shows its protective effect by interacting with p47-phox and its domains, although this requires further studies for confirmation.

\section{Conclusions}

Our study demonstrated that the protective effect of SN attenuates Ang II-induced podocyte autophagy and that SN-mediated ROS generation decreased in part via regulation of the NOX subunit $\mathrm{p} 47$-phox translocation to the membrane.

\section{Disclosure Statement}

All authors declare that they have no competing interests.

\section{Acknowledgments}

We thank Dr. Moin A. Saleem (University of Bristol, UK) for providing the immortalized human podocytes (AB8/13).

\section{Reference}

1 Pichler Sekulic S, Sekulic M: Rheological influence upon the glomerular podocyte and resultant mechanotransduction. Kidney Blood Press Res 2015;40:176-187.

2 Galluzzi L, Morselli E, Vicencio JM, Kepp 0, Joza N, Tajeddine N, Kroemer G: Life, death and burial: multifaceted impact of autophagy. Biochem Soc Trans 2008;36:786-790.

3 Susztak K, Raff AC, Schiffer M, Bottinger EP: Glucose-induced reactive oxygen species cause apoptosis of podocytes and podocyte depletion at the onset of diabetic nephropathy. Diabetes 2006;55:225-233.

4 Yang M, Wang B, Li M, Jiang B: Connexin 43 is involved in aldosterone-induced podocyte injury. Cell Physiol Biochem 2014;34:1652-1662.

5 Wang C, Li C, Peng H, Ye Z, Zhang J, Liu X, Lou T: Activation of the Nrf2-ARE pathway attenuates hyperglycemia-mediated injuries in mouse podocytes. Cell Physiol Biochem 2014;34:891-902.

6 Asanuma K, Tanida I, Shirato I, Ueno T, Takahara H, Nishitani T, Kominami E, Tomino Y: MAP-LC3, a promising autophagosomal marker, is processed during the differentiation and recovery of podocytes from PAN nephrosis. FASEB J 2003;17:1165-1167.

7 Mizushima N, Yamamoto A, Matsui M, Yoshimori T, Ohsumi Y: In vivo analysis of autophagy in response to nutrient starvation using transgenic mice expressing a fluorescent autophagosome marker. Mol Biol Cell 2004;15:1101-1111.

8 Riediger F, Quack I, Qadri F, Hartleben B, Park JK, Potthoff SA, Sohn D, Sihn G, Rousselle A, Fokuhl V, Maschke U, Purfurst B, Schneider W, Rump LC, Luft FC, Dechend R, Bader M, Huber TB, Nguyen G, Muller DN: Prorenin receptor is essential for podocyte autophagy and survival. J Am Soc Nephrol 2011;22:21932202.

9 Li G, Li CX, Xia M, Ritter JK, Gehr TW, Boini K, Li PL: Enhanced epithelial-to-mesenchymal transition associated with lysosome dysfunction in podocytes: role of p62/Sequestosome 1 as a signaling hub. Cell Physiol Biochem 2015;35:1773-1786.

10 Tharaux PL, Huber TB: How many ways can a podocyte die? Semin Nephrol 2012;32:394-404.

11 Yadav A, Vallabu S, Arora S, Tandon P, Slahan D, Teichberg S, Singhal PC: ANG II promotes autophagy in podocytes. Am J Physiol Cell Physiol 2010;299:C488-496.

12 Ma T, Zhu J, Chen X, Zha D, Singhal PC, Ding G: High glucose induces autophagy in podocytes. Exp Cell Res 2013;319:779-789. 


\section{Kidney \\ Blood Pressure Research}

Kidney Blood Press Res 2016;41:158-167

\begin{tabular}{l|l}
\hline DOI: 10.1159/000443417 & (C) 2016 The Author(s). Published by S. Karger AG, Base
\end{tabular}

Published online: February 29, 2016

www.karger.com/kb

13 Azad MB, Chen Y, Gibson SB: Regulation of autophagy by reactive oxygen species (ROS): implications for cancer progression and treatment. Antioxid Redox Signal 2009;11:777-790.

14 Ravikumar B, Sarkar S, Davies JE, Futter M, Garcia-Arencibia M, Green-Thompson ZW, Jimenez-Sanchez M, Korolchuk VI, Lichtenberg M, Luo S, Massey DC, Menzies FM, Moreau K, Narayanan U, Renna M, Siddiqi FH, Underwood BR, Winslow AR, Rubinsztein DC: Regulation of mammalian autophagy in physiology and pathophysiology. Physiol Rev 2010;90:1383-1435.

15 Chen Y, Azad M, Gibson S: Superoxide is the major reactive oxygen species regulating autophagy. Cell Death Differ 2009;16:1040-1052.

16 van Kats JP, Schalekamp MA, Verdouw PD, Duncker DJ, Danser AH: Intrarenal angiotensin II: interstitial and cellular levels and site of production. Kidney Int 2001;60:2311-2317.

17 Scherz-Shouval R, Elazar Z: Regulation of autophagy by ROS: physiology and pathology. Trends Biochem Sci 2011;36:30-38.

18 Li L, Tan J, Miao Y, Lei P, Zhang Q: ROS and Autophagy: Interactions and Molecular Regulatory Mechanisms. Cell Mol Neurobiol 2015, DOI 10.1007/s10571-015-0166-x.

19 Bin Wang S, Hee Chae Y, Yong Jang J, Hyun Min J, Young Baek J, Kim M, Park Y, Seo Hwang G, Ryu JS, Chang TS: Kaempferol suppresses collagen-induced platelet activation by inhibiting NADPH oxidase and protecting SHP-2 from oxidative inactivation. Free Radic Biol Med 2015, DOI 10.1016/j. freeradbiomed.2015.01.018.

20 Brandes RP, Weissmann N, Schroder K: Nox family NADPH oxidases: Molecular mechanisms of activation. Free Radic Biol Med 2014;76:208-226.

21 Ushio-Fukai M: Localizing NADPH oxidase-derived ROS. Sci STKE 2006;2006:re8.

22 Cheng Y, Zhang J, Hou W, Wang D, Li F, Zhang Y, Yuan F: Immunoregulatory effects of sinomenine on the T-bet/GATA-3 ratio and Th1/Th2 cytokine balance in the treatment of mesangial proliferative nephritis. Int Immunopharmacol 2009;9:894-899.

23 Cheng Y, Li F, Wang D, Zhang Y, Yuan F, Zhang J: Sinomenine inhibits the expression of PD-L1 in the peripheral blood mononuclear cells of mesangial proliferative nephritis patients. Mol Med Rep 2013;7:1223-1228.

24 Zhao XX, Peng C, Zhang H, Qin LP: Sinomenium acutum: a review of chemistry, pharmacology, pharmacokinetics, and clinical use. Pharm Biol 2012;50:1053-1061.

25 Qian L, Xu Z, Zhang W, Wilson B, Hong JS, Flood PM: Sinomenine, a natural dextrorotatory morphinan analog, is anti-inflammatory and neuroprotective through inhibition of microglial NADPH oxidase. J Neuroinflammation 2007;4:23.

26 Shukla SM, Sharma SK: Sinomenine inhibits microglial activation by Abeta and confers neuroprotection. J Neuroinflammation 2011;8:117.

27 Ting Y, Zhenhong N, Wei G, Fengtian H: Anti-inflammation activity of sinomenine-induced autophagy in EA.hy926 cells. J Third Military Med University 2013;35:1084-1087.

28 Jiang Y, Gao M, Wang W, Lang Y, Tong Z, Wang K, Zhang H, Chen G, Liu M, Yao Y, Xiao X: Sinomenine Hydrochloride Protects against Polymicrobial Sepsis via Autophagy. Int J Mol Sci 2015;16:2559-2573.

29 Saleem MA, O'Hare MJ, Reiser J, Coward RJ, Inward CD, Farren T, Xing CY, Ni L, Mathieson PW, Mundel P: A conditionally immortalized human podocyte cell line demonstrating nephrin and podocin expression. J Am Soc Nephrol 2002;13:630-638.

30 Sato S, Yanagihara T, Ghazizadeh M, Ishizaki M, Adachi A, Sasaki Y, Igarashi T, Fukunaga Y: Correlation of autophagy type in podocytes with histopathological diagnosis of IgA nephropathy. Pathobiology 2009;76:221-226.

31 Touyz RM, Yao G, Schiffrin EL: c-Src induces phosphorylation and translocation of p47phox: role in superoxide generation by angiotensin II in human vascular smooth muscle cells. Arterioscler Thromb Vasc Biol 2003;23:981-987.

32 Filomeni G, De Zio D, Cecconi F: Oxidative stress and autophagy: the clash between damage and metabolic needs. Cell Death Differ 2015;22:377-388.

33 Ren J, Taegtmeyer H: Too Much or Not Enough of a Good Thing - the Janus Faces of Autophagy in Cardiac Fuel and Protein Homeostasis. J Mol Cell Cardiol 2015, DOI 10.1016/j.yjmcc.2015.03.001

34 Landmesser U, Cai H, Dikalov S, McCann L, Hwang J, Jo H, Holland SM, Harrison DG: Role of p47phox in Vascular Oxidative Stress and Hypertension Caused by Angiotensin II. Hypertension 2002;40:511-515.

35 Seshiah PN, Weber DS, Rocic P, Valppu L, Taniyama Y, Griendling KK: Angiotensin II stimulation of NAD(P)H oxidase activity: upstream mediators. Circ Res 2002;91:406-413. 